\title{
PENERAPAN METODE KARYAWISATA PADA PERANAN PERS MENINGKATKAN HASIL BELAJAR SISWA KELAS XII SMKN 11 JAKARTA
}

\section{Sri Wahyuningsih}

How to cite : Wahyuningsih, Sri., 2021. PENERAPAN METODE KARYAWISATA PADA PERANAN PERS MENINGKATKAN HASIL BELAJAR SISWA KELAS XII SMKN 11 JAKARTA. Jurnal Penelitian dan Penilaian Pendidikan. 3(2). 212 - 218.

To link to this article : https://doi.org/10.22236/jppp.v3i1.7306

(C2021. The Author(s). This open access article is distributed under a Creative Commons Attribution (CC BY-SA) 4.0 license.

Published Online on 30 July 2021 


\title{
PENERAPAN METODE KARYAWISATA PADA PERANAN PERS MENINGKATKAN HASIL BELAJAR SISWA KELAS XII SMKN 11 JAKARTA
}

\author{
Sri Wahyuningsih ${ }^{1} \otimes$ \\ ${ }^{1}$ Sekolah Menengah Kejuruan Negeri 11 Jakarta \\ E-mail: $\quad$ sri.wahyuningsih@gmail.com ${ }^{l)}$
}

Received : 20 April 2021

Accepted: 25 July 2021

Published Online: 30 July 2021

\begin{abstract}
Abstrak
Penelitian Tindakan Kelas dengan judul Penerapan Metode Karyawisata Pada Peranan Pers Meningkatkan Hasil Belajar Siswa Kelas XII AKL1 SMKN 11 Jakarta tahun 2019/2020.Sebuah penelitian yang diawali dengan adanya kebosanan siswa dalam belajar yang mengakibatkan nilai hasil belajar rendah, maka dilakukan terobosan baru belajar dengan menggunakan metode pembelajaran karyawisata, tujuannya adalah meningkatkan hasil belajar siswa. Metode ini menerapkan pemecahan masalah dari tugas yang di sampaikan oleh guru melalui bentuk karyawisata yang dilakukan secara berkelompok dengan tujuan wisata yang berbeda tetapi dengan misi yang sama .penelitian dilakukan dengan 3 siklus yaitu siklus pertama berupa diskusi tempat tujuan yang akan didatangi, siklus kedua melakukan perjalanan wisata, siklus tiga mempresentasikan hasil kunjungan dan membuat laporan tertulis dalam bentuk tulisan koran.Hasil tes pengetahuan pada siklus pertama adalah 66,85 siklus kedua 81,14 dan siklus ketiga 81,42 sementara hasil pengamatan siklus pertama 81,25 siklus kedua 84.00 dan siklus ketiga 86,05.
\end{abstract}

Kata Kunci : Hasil belajar, Metode Karyawisata, Peranan Pers.

\begin{abstract}
Classroom Action Research with the title Application of the Field Trip Method in the Role of the Press to Increase Student Learning Outcomes in Class XII AKL1 SMKN 11 Jakarta in 2019/2020. A research that began with student boredom in learning which resulted in low learning achievement scores, a new learning breakthrough was made by using field trip learning method, the goal is to improve student learning outcomes. This method applies problem solving from assignments conveyed by the teacher through the form of field trips which are carried out in groups with different tourist destinations but with the same mission. The research was carried out in 3 cycles, namely the first cycle in the form of discussing destinations to be visited, the second cycle traveling tour, cycle three presented the results of the visit and made a written report in the form of a newspaper. The results of the knowledge test in the first cycle were 66.85 , the second cycle was 81.14 and the third cycle was 81.42 while the observations of the first cycle were 81.25 , the second cycle was 84.00 and the third cycle was 81.25 . third 86.05 .
\end{abstract}

Keywords: Field Trip Method, Learning Outcomes, The Role of The Press.

This is an open access article under the Creative Commons Attribution 4.0 International License 


\section{PENDAHULUAN}

Sekolah merupakan basis pendidikan,karenanya harus memiliki tujuan yang jelas, antara visi dan misi sekolah hendaknya cocok, peserta didik dan guru bisa salingberkolaborasi untuk menghaslkan keunggulan sekolah, akan tetapi untuk menciptakan keunggulan tersebut banyak terdapat rintangan, baik dari siswa, guru maupun sarana sekolah. Penelitian tindakan kelas adalah cara untuk mengevaluasi hasil kerja guru dan hasil belajar siswa.

Pemilihan metode karyawisata pada penelitian tindakan kelas ini berawal dari adanya keinginan menghilangkan rasa suntuk siswa yang selalu berkutet disekolah dengan bimbingan guru, adanya rasa suntuk menyebabkan pembelajaran mengalami kemunduran dalam nilai,banyak siswa mendapat nilai kurang mencapai KKM, disamping itu sebagai suatu penyegaran agar siswa dalam persiapan menuju UAN sudah memiliki rasa kebersamaa, karenanya perlu diadakan metode baru agar hasil belajar siswa mengalami peningkatan diantaranya melalui metode karyawisata. Pelaksanaan metode dilakukan dengan cara mencari KD yang kemudian di sesuaikan, dan dalam pelaksanaannya siswa secara berkelompok melakukan kunjungan wisata ke berbagai tempat wisata atau instansi pemerintah, pada saat mereka melaksanakan tugas tidak di dampingi oleh guru akan tetapi mereka sudah di persiapkan tentang apa saja yang harus di kerjakan pada saat sebelum melakukan wisata, saat wisata dan setelah mengadakan wisata.Perumusan masalah pada penelitian tindakan kelas ini adalah bagaimana penerapan metode karyawisata pada peranan Pers meningkatkan hasil belajar siswa kelas XII AKL 1 SMKN Jakarta tahun 2019/2020.Adapun tujuan penelitian ini adalah mengetahui bagaimana penerapan metode karyawisata pada peranan pers meningkatkan hasil belajar siswa kelas XII AKL 1 SMKN 11 Jakarta tahun 2019/2020.

\section{METODE PENELITIAN}

Penelitian dilakukan di SMK Negeri 11 Jakarta pada kelas XII AKL 1 dan dilaksanakan pada semester genap tahun 2019/2020. Populasi dan Sampel Penelitian adalah siswa kelas XII AKL 1 terdiri dari 35 siswa yang ikut dalam bimbingan pembelajaran semester genap untuk tahun pelajaran 2019/2020. Desain penelitian dilakukan melalui 4 tahap yaitu perencanaan, tindakan, pengamatan dan refleksi. Dalam tahap perencanaan di atur tentang strategi pembelajaran metode karyawisata dan stuktur pengelolaan pembelajarannya, kemudian jenis media yang dapat diterapkan, aspek-aspek yang terkait dengan cara mengajar,substansi materi yang disampaikan dan tehnik penilaian yang digunakan. Setelah permasalahan diidentifikasi, maka ditentukan tindakan yang berkaitan dengan metode karyawisata yaitu mengembangkan dan menerapkan metode karyawisata pada mata pelajaran PKn.

Tahap tindakan dilakukan dengan 3 siklus, siklus pertama berupa pemilihan topik kajian,kemudian membuat rancangan pelaksanaan metode karyawisata, menentukan tempat, membagi kelompok,menentukan ketua kelompok,menentukan tempat yang akan di kunjungi,membuat pertanyaan yang akan diajukan,menentukan jadwal batas kunjungan wisata ,membuat perjanjian antar anggota kelompok,melaporkan tentang tempat kunjungan, dan mempersiapkan sarana.siklus kedua menjelaskan tujuan karyawisata, menjelaskan garis besar materi peranan pers .siklus ketiga siswa melakukanpresentasi dari hasil kunjungan dan membuat tulisan pelaporan tentang perjalanan wisatayang dilakukan selayaknya tulisan pers melalu komputer dan desain foto grafer.tugas pengamat adalah mencatat, mengumpulkan data,dan mendokumentasikan.Adapun gambaran tentang 
penelitian tindakan kelas dapat di desain sebagai berikut :

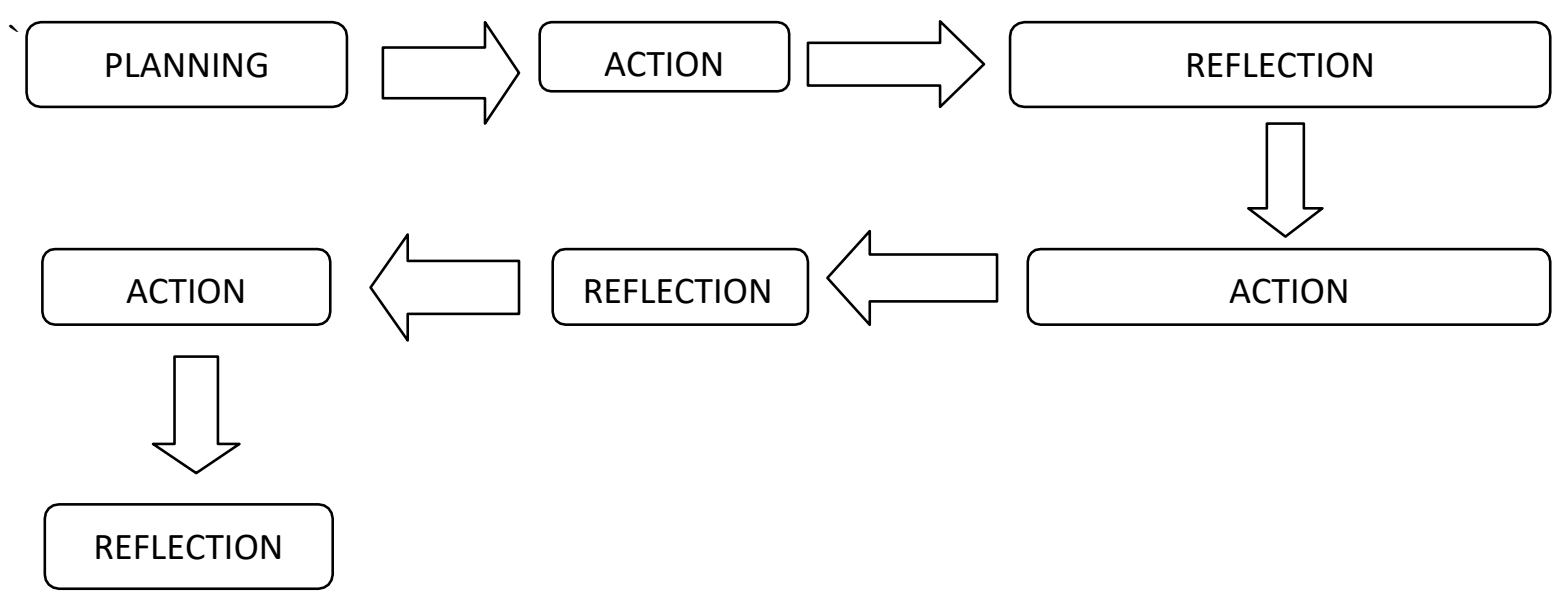

\section{Kinerja Penelitian}

Kinerja penelitian dilakukan dengan tiga siklus, proses berulangnya tindakan dalam setiap siklus ditentukan beberapa ketercapaian indikator antara lain 80 persen siswa siswa memiliki antusias untuk melakukan kunjungan wisata, mempersiapkan, melaksanakan dan melaporkandalam bentuk presentasi dan laporan tertulis.saat presentasi siswa sudah membuat laporan tertulis yang dapat dikritisi oleh teman lainnya dan di perbaikin oleh kelompok sebelum diserahkan ke guru.Dari hasil pelaksanaan metode karyawisata pada peranan pers $80 \%$ lebih siswa dapat melaksanakan tugas tersebut dengan baik dan meningkat hasil belajarnya.

\section{HASIL PEMBAHASAN}

Tabel I

Hasil Tes Siklus I

\begin{tabular}{|l|l|l|}
\hline Kelas & Nilai & Frekwensi \\
\hline 1 & 0 & 1 \\
\hline 2 & 30 & 1 \\
\hline 3 & 50 & 5 \\
\hline 4 & 60 & 9 \\
\hline 5 & 75 & 8 \\
\hline 6 & 80 & 9 \\
\hline 7 & 90 & 2 \\
\hline \multicolumn{2}{|l}{} \\
\hline
\end{tabular}

Dari data tersebut jika di diagram batangkan akan terlihat sebagai berikut : 


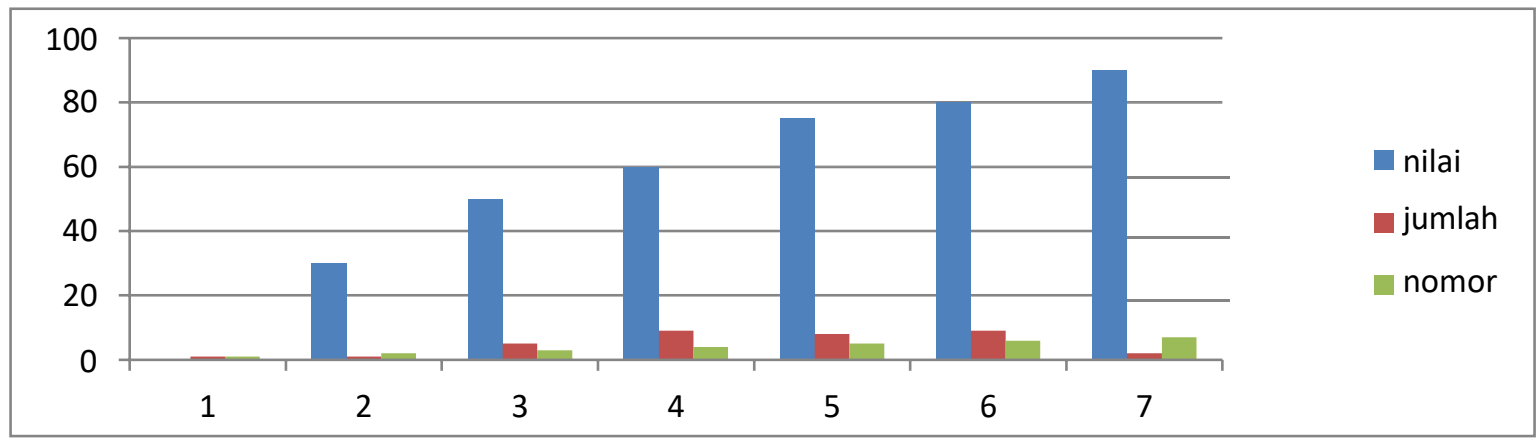

Tabel 2

Data Hasil Pengamatan Siklus I

\begin{tabular}{clc}
\hline No & \multicolumn{1}{c}{ Aspek } & Jumlah \\
\hline 1 & Kekompakan memilih tempat tujuan wisata & 140 \\
\hline 2 & Kekompakan menentukan jadwal kunjungan wisata & 163 \\
\hline 3 & Kesigapan menerima tugas karyawisata & 140 \\
\hline 4 & Kemampuan menyususn pertanyaan untukbahan laporan & 140 \\
\hline 5 & Kesesuaian jadwal dengan rencana keberangkatan kunjungan & 128 \\
\hline & Skor tertinggi teoritik & 175 \\
\hline
\end{tabular}

Tabel 3

\begin{tabular}{|c|c|c|c|c|c|c|}
\hline \multicolumn{6}{|c|}{ Hasil Tes Siklus Kedua } & \multirow[b]{3}{*}{ nilai } \\
\hline 80 & Kelas & & ilai & & Frekuensi & \\
\hline 60 & 1 & & 78 & & 5 & \\
\hline 40 & 2 & & 30 & & 20 & Eujumlah \\
\hline 20 & 3 & & 35 & & 10 & \\
\hline $\begin{array}{r}20 \\
0\end{array}$ & 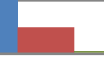 & ah & 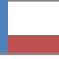 & & 35 & nomor \\
\hline & 1 & 2 & 3 & 4 & 5 & \\
\hline
\end{tabular}

Dari data tersebut jika didiagram batangkan akan terlihat sebagai berikut :

Tabel 4

Data Hasil Pengamatan Siklus 2

\begin{tabular}{clc}
\hline No. & Aspek & Jumlah \\
\hline 1 & Kemampuan memperoleh informasi & 140 \\
\hline 2 & Kemampuan mengolah informasi menjadi bahan laporan & 140 \\
\hline 3 & Kemampuan membuat dokumentasi & 140 \\
\hline 4 & Kemampuan mempresentasikan hasil kunjungan wisata & 175 \\
\hline 5 & Kemampuan menjawab soal yang disediakan oleh guru & 140 \\
\hline 6 & Skor tertinggi teoritik & $\mathbf{1 7 5}$ \\
\hline
\end{tabular}


Tabel 5

Hasil Tes Siklus Ke 3

\begin{tabular}{ccc}
\hline Kelas & Nilai & Frekuensi \\
\hline 1 & 78 & 10 \\
\hline 2 & 80 & 18 \\
\hline 3 & 90 & 7 \\
\hline & Jumlah & $\mathbf{3 5}$
\end{tabular}

Dari data di atas jika didiagram batangkan akan terlihat sebagai berikut :

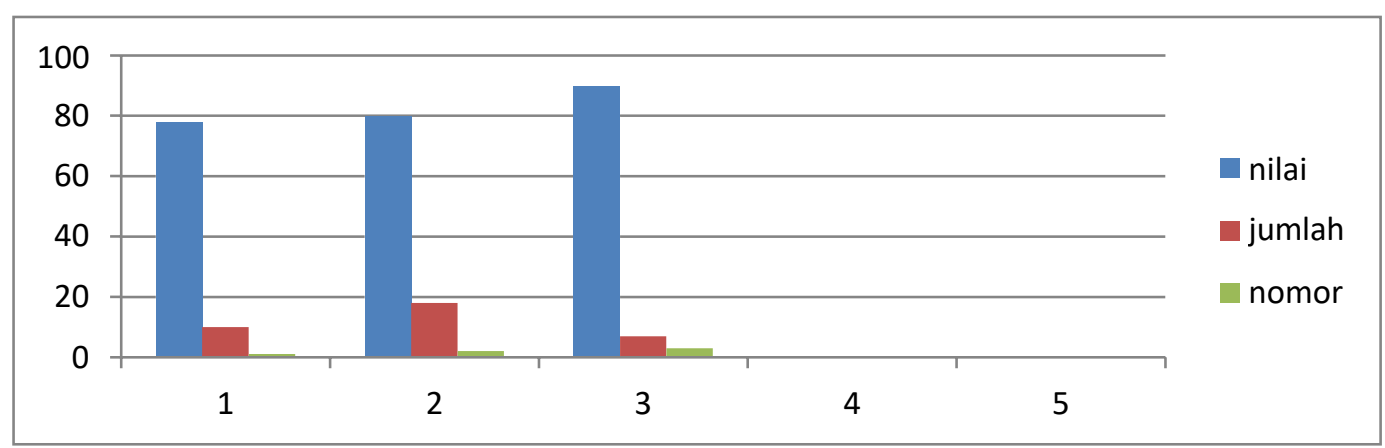

Tabel 6

Data Hasil Pengamatan Pada Siklus 3

\begin{tabular}{clc}
\hline NO & Aspek & Jumlah \\
\hline 1 & Ketepatan Penyerahan Hasil Laporan Kunjungan & 140 \\
\hline 2 & Keserasian antara dokumentasi dengan bahan berita & 151 \\
\hline 3 & Kemampuan membuat laporan dalam bentuk berita koran & 151 \\
\hline 4 & Kerapihan dalam pengetikan bahan laporan & 160 \\
\hline 5 & Ketepatan dalam penyusunan bahan laporan & 151 \\
\hline & Skor tertinggi teoritik & $\mathbf{1 7 5}$ \\
\hline
\end{tabular}

\section{Analisa Data}

Data Hasil Tes Standart Kompetensi Peranan Pers Pada Mata Pelajaran PKn

Tabel 7

Nilai-rata -rata tes kompetensi

\begin{tabular}{lrrr} 
Rata-rata & Siklus 1 & Siklus 2 & Siklus 3 \\
\cline { 2 - 4 } & $\mathbf{6 6 , 8 5}$ & $\mathbf{8 1 , 1 4}$ & $\mathbf{8 1 , 4 2}$
\end{tabular}

Data Hasil Pengamatan metode karyawisata pada peranan pers dapat di lihat dalamtabel sebagai berikut: 
Tabel 8

Hasil Pengamatan Metode Karyawisata

\begin{tabular}{|c|c|c|c|c|}
\hline No & Aspek & Siklus 1 & Siklus 2 & Siklus 3 \\
\hline 1 & Kekompakan memilih tempat tujuan wisata & $80.00 \%$ & & \\
\hline 2 & $\begin{array}{l}\text { Kekompakan menentukan } \\
\text { kunjungan }\end{array}$ & $93,14 \%$ & & \\
\hline 3 & Kesigapan menerima tugas karyawisata & $80,00 \%$ & & \\
\hline 4 & $\begin{array}{l}\text { Kemampuan menyusun pertanyaan untuk } \\
\text { bahan laporan }\end{array}$ & $80,00 \%$ & & \\
\hline 5 & $\begin{array}{l}\text { Kesesuaian jadwal dengan rencana } \\
\text { keberangkatan kunjungan }\end{array}$ & $73,14 \%$ & & \\
\hline 6 & Kemampuan memperoleh informasi & & $80,00 \%$ & \\
\hline 7 & $\begin{array}{l}\text { Kemampuan mengolah informasi menjadi } \\
\text { bahan laporan }\end{array}$ & & $80,00 \%$ & \\
\hline 8 & Kemampuan membuat dokumentasi & & $80,00 \%$ & \\
\hline 9 & $\begin{array}{l}\text { Kemampuan mempresentasikan hasil } \\
\text { kunjungan wisata }\end{array}$ & & $100,00 \%$ & \\
\hline 10 & $\begin{array}{l}\text { Kemampuan menjawab soal yang } \\
\text { disediakan oleh guru }\end{array}$ & & $80,00 \%$ & \\
\hline 11 & $\begin{array}{l}\text { Ketepatan Penyerahan Hasil Laporan } \\
\text { Kunjungan }\end{array}$ & & & $80,00 \%$ \\
\hline 12 & $\begin{array}{l}\text { Keserasian antara dokumentasi dengan } \\
\text { bahan berita }\end{array}$ & & & $86,28 \%$ \\
\hline 13 & $\begin{array}{l}\text { Kemampuan membuat laporan dalam } \\
\text { bentuk berita koran }\end{array}$ & & & $86,28 \%$ \\
\hline 14 & $\begin{array}{l}\text { Kerapihan dalam pengetikan bahan } \\
\text { laporan }\end{array}$ & & & $91.42 \%$ \\
\hline \multirow[t]{2}{*}{15} & $\begin{array}{l}\text { Ketepatan dalam penyusunan bahan } \\
\text { laporan }\end{array}$ & & & $86,28 \%$ \\
\hline & Rata-rata & $\mathbf{8 1 , 2 5 \%}$ & $84,00 \%$ & $\mathbf{8 6 , 0 5 \%}$ \\
\hline
\end{tabular}

\section{Pembahasan}

Pada siklus pertama nilai rata-rata hasil test standart kompetensi Peranan Pers dengan metode karyawisata di SMKN 11 Jakarta adalah 66,85 artinya ketercapaian kompetensi pada siklus 1 masih rendah dan berada di bawah KKM, sementara hasil analisa pengamatan 81,25 sudah diatas KKM, walaupun demikian masih perlu dilanjutkan pada siklus ke dua.Pada siklus ke kedua hasil tes mengalami peningkatan ditunjukkan dengan adanya hasil tes rata-rata 81,14 sementara hasil analisa pengamatan $84,00 \%$ pada siklus ketiga rata-rata hasil test lebih meningkat lagi yaitu menjadi 81,42 sementara hasil analisa pengamatan rata-rata 86,05\%. KKM ditetapkan sekolah adalah 80.00. 


\section{KESIMPULAN}

Dari hasil analisa di atas maka dapat disimpulkan bahwa :"Metode Karyawisata pada Peranan Pers dapat meningkatkan hasil belajar siswa kelas XII AKL 1 SMKN 11 Jakarta tahun 2019/2020". Implikasinya merujuk pada hasil penelitian ini maka penggunaan metode karyawisata dapat meningkatkan hasil pembelajaran PKn, olehkarenannya metode ini dapat dijadikan metode alternatif bagi sebuah pembelajaran.

Penggunaan metode karyawisata dapat pula divariasikan dengan metode lain sehingga menghasilkan kegiatan pembelajaran yang lebih menyenangkan,siswa dididik untuk mandiri dalam kelompok,menciptakan rasa kebersamaan, tanggung jawab dan kedisiplinan,karenanya cocok untuk menciptakan generasi karakter bangsa.

\section{DAFTAR PUSTAKA}

Amirudin dan Asikin Zaenal,(2012) Pengantar Metode Penelitian,Jakarta,Rajawali pers. Ayu Lestari dan kawan-kawan, (2020), Jurnal PETIK Volume 6, no 1,Maret Barus,SediaWiling,(2010),Jurnalistik” Petunjuk Tehnis Menulis Berita, Jakarta:Erlangga

Jumiati,Penerapan Metode Karyawisata pada konsep dasar IPA MI/SD,PGMI,Vol 2,No.2,2017 hal 21

Mansur,R(2018).Belajar Jalan Perubahan Menuju Kemajuan Vicratina:Jurnal

PendidikanIslam,3

Djuroto, Toto, (2000) Manajemen Penerbitan Pers, Bandung: Penerbit Remaja Komalasari,(2017) Pendidikan Karakter,Malang: Refika Aditama Masduki,(2004) Kebebasan Pers dan Kode Etik Jurnalistik, (Catatan Lapangan), Yogyakarta: UUI Pers.

Nong Bola, Yanto,(2020) sosiological education vol 1, no 1,Jurnal Unmuh, Kupang Nyoman, Gusti Oka, (2020) dalam open jurnal systems volume 14 no 7 Februari 2020 Sardiman, A.M. (2004) Interaksi dan Motivasi Belajar, Jakarta: PT. Raja Grafindo Sanjaya,Wina,(2010),Strategi Pembelajaran Berorientasi Standart Proses Pendidikan, Jakarta: Kencana.

Sujana, Nana. (2010) Cara Belajar Siswa Aktif dalam Proses Belajar Mengajar, Bandung:Sinar Baru Algesindo

Sukmadinata, Nana Syaodih. (2009). Metode Penelitan Pendidikan, Bandung: Rosdakarya.

Warista Bambang. (2008). Tehnologi Pembelajaran, Landasan dan Aplikasinya, Jakarta: Rineka Cipta

Warsono dan Haryanto, (2012). Pembelajaran Aktif: Teori dan Assesmen ,Bandung: Rosdakarya. 